\title{
Comparative Evaluation of Different Surface Treatments on the Repair Shear Bond Strength of Three Nanohybrid Composites: An in vitro Study
}

\author{
${ }^{1}$ Arvind K Alexander, ${ }^{2} \mathrm{R}$ Mohana Priya, ${ }^{3}$ Sheerin Sarthaj, ${ }^{4} \mathrm{~S}$ Maria Antony
}

\begin{abstract}
Aim: To evaluate the effects of different surface treatments on the repair bond strength of three different nanohybrid composites, namely conventional nanohybrid, bulk fill, and ceramicincorporated composites.
\end{abstract}

Materials and methods: A split mold of height $5 \times 5 \mathrm{~mm}$ in diameter was taken; 60 composite blocks were prepared based on three composites used. Group I: Kerr nanohybrid, group II: Tetric N-Ceram Bulk Fill, and group III: NanoCeram. Composite material was restored with incremental layering technique of $2 \mathrm{~mm}$ thickness. Aging of the composite blocks was achieved by storing them in distilled water for 1 week and then thermocycling. The samples were surface treated as subgroup $A$ : sandblasting with silica particles, subgroup B: coarse grit diamond bur, subgroup C: etching with $10 \%$ hydrofluoric acid, and subgroup D: control group. Surface roughness of each surface-treated sample was evaluated using three-dimensional (3D) profilometer. A silane coupling agent and an adhesive agent were applied. Composite blocks were restored with the respective composite resins using a repair mold. A shearing force test was performed using universal testing machine. A load was applied to the interface at a crosshead speed of $0.5 \mathrm{~mm} /$ minute until fracture. Analyses were performed using analysis of variance (ANOVA) and post hoc Tukey test.

Results: Highest shear bond strength was observed in composites surface treated with sandblasting followed by bur and hydrofluoric acid. The lowest shear bond strength was observed in the control group.

Conclusion: Sandblasting surface treatment of Kerr composite manifested the highest bond strength, followed by Tetric $\mathrm{N}$-Ceram and NanoCeram groups. Bur treatment of Tetric $\mathrm{N}$-Ceram showed the higher bond strength values compared with the other groups. HF3 surface treatment of NanoCeram composite presented inferior bond strength values. Repair bond strength of aged nanohybrid resins could be improved with sandblasting, silane, and adhesive resin application compared with other surface treatments.

Keywords: Nanohybrid, Sand blasting, Shear bond strength, Silane coupling agent, Surface treatment.

\footnotetext{
${ }^{1}$ Professor, ${ }^{2,3,4}$ Postgraduate Student

${ }^{1-4}$ Department of Conservative Dentistry and Endodontics, Rajas Dental College \& Hospital, Tirunelveli, Tamil Nadu, India

Corresponding Author: Arvind K Alexander, Professor Department of Conservative Dentistry and Endodontics, Rajas Dental College \& Hospital, Tirunelveli, Tamil Nadu, India, Phone: +919443379002, e-mail: kumarsdentalclinic@gmail.com
}

How to cite this article: Alexander AK, Priya RM, Sarthaj S, Antony SM. Comparative Evaluation of Different Surface Treatments on the Repair Shear Bond Strength of Three Nanohybrid Composites: An in vitro Study. Cons Dent Endod J 2018;3(1):22-26.

\section{Source of support: Nil}

Conflict of interest: None

\section{INTRODUCTION}

The search for an ideal esthetic restorative material started with the era of direct-filling gold restorations. There had been a number of restorative materials used, such as dental amalgam, Glass ionomer cement, and the revolutionary introduction of resin-based composites in dentistry. The usage of composites was encouraged owing to its advantages like better esthetics, bonding to tooth structure, and cost-effectiveness when compared with indirect restorative treatments. ${ }^{1}$ It has some disadvantages like discoloration, wears, fractures, or defects with time, which may require replacements. ${ }^{2-4}$ At times, when composite restoration fractures, total replacement of fractured restoration opposes the current practice of minimally invasive dentistry to minimize loss of sound tooth structure and to prevent potential damage to the pulp. Hence, repair of defective composite restoration has become a procedure of choice. 5,6

The adhesion between the incremental composite layers relies on the presence of oxygen-inhibited layers of unpolymerized resin, where unreacted methacrylate groups are present. ${ }^{7}$ These unreacted $\mathrm{C}=\mathrm{C}$ bonds facilitate bonds with the next increment. ${ }^{8}$ Aged composites have diminished the amount of unreacted double bonds, due to various oral environment factors as salivary $\mathrm{pH}$, moist conditions, instability within resin matrix and filler particles due to hydrolytic degradation of composite restoration. ${ }^{9}$ As a consequence, adhesion of new composite to aged one is unpredictable. ${ }^{10,11}$

The bond strength between old and new composite interface depends on various surface treatments that include both mechanical and chemical methods. Each surface treatment provides a different pattern of roughness that may have its effects on bonding to the repair composites. ${ }^{12,13}$ Mechanical surface treatment involves roughening 
with rotary diamond bur that creates macromechanical retention or sandblasting the surface with $\mathrm{Al}_{2} \mathrm{O}_{3}$ particles that promote micromechanical retention. ${ }^{14,15}$ Roughening of the composite surface can also be achieved by $\mathrm{H}_{3} \mathrm{PO}_{4}$ acid or HF3 acid etching and, recently, lasers. ${ }^{16}$

Chemical surface treatment involves application of silane coupling agent followed by low-viscosity adhesive system. Sandblasting with silica modified $\mathrm{Al}_{2} \mathrm{O}_{3}$ particles promotes incorporation of silica particles along with surface roughening, which facilitates chemical adhesion. ${ }^{17,18}$ Silanating the resin surface by silane coupling agent facilitates the bonding with the matrix of repair composite due to the addition of Si-O group on the exposed filler particles of the roughened aged composite.

Various commercial brands of composites with different compositions are available, and the type of resin seems to be the primary factor influencing the repair bond strength of the composites. The current study evaluated the bond strength of nanohybrid composites using different surface treatments.

\section{AIM}

To evaluate the effects of different surface treatments on the repair shear bond strength of three different composites, namely conventional nanohybrid, bulk fill nanohybrid, and ceramic-incorporated nanohybrid composites.

\section{MATERIALS AND METHODS}

Ethical approval was not obtained because it involved in vitro preparation of composite blocks as it was a noninvasive procedure.

\section{Sample Preparation}

A stainless steel split mold of height $5 \times 5 \mathrm{~mm}$ in diameter was taken. Sixty composite blocks were prepared using the split mold based on three different nanohybrid restorative materials used $(n=20)$. Table 1 represents the characteristics of materials. Group I: Kerr nanohybrid (Herculite Précis, Kerr), group II: Tetric N-Ceram Bulk Fill (Ivoclar Vivadent), and group III: NanoCeram Bright (DMP, USA). The split mold was placed over the glass plate, and each composite material was restored with incremental layering technique of $2 \mathrm{~mm}$ thickness. Each layer was light polymerized for 20 seconds using light-emitting diode (LED) light curing unit with a light intensity of 800 to $1000 \mathrm{Mw} / \mathrm{cm}^{2}$ (Bluephase, Ivoclar Vivadent, Schaan, Liechtenstein). Mylar strip was placed over the last increment and cured to minimize the formation of oxygen-inhibited layer and to create a smooth surface. The split mold was then removed, and samples were cured of all the sides for 20 seconds to achieve complete polymerization.

To effectively differentiate between the old and the new composite resins, two different composite shades were used: A4 for preparation of original composite blocks, and A2 shade for preparation of repair composite blocks.

\section{Aging Procedure}

Aging of the composite blocks was achieved by storing them in distilled water in an incubator at a temperature of $37^{\circ} \mathrm{C}$ for 1 week and then thermocycling at $55 \pm 5^{\circ} \mathrm{C}$ with a dwell time of 30 seconds and transfer time of 10 seconds. After that, each group was further divided into four subgroups according to the surface treatments used.

\section{Surface Treatments}

Subgroup A: The samples were surface treated using a sandblaster device (APM Sterngold extraoral sandblaster) with silica particles (110 $\mu \mathrm{m}$ particle size). The tip was

Table 1: Characteristics of materials

\begin{tabular}{|c|c|c|c|c|}
\hline Composite resin & $\begin{array}{l}\text { Brand } \\
\text { (manufacturer) }\end{array}$ & Composition (resin matrix) & Composition (filler type) & $\begin{array}{l}\text { Filler loading } \\
\text { (weight/volume\%) }\end{array}$ \\
\hline Herculite Precis & $\begin{array}{l}\text { Kerr, Orange, } \\
\text { CA, USA }\end{array}$ & $\begin{array}{l}\text { Uncured methacrylate } \\
\text { ester monomers, } \mathrm{TiO}_{2} \text {, } \\
\text { and pigments }\end{array}$ & $\begin{array}{l}\text { Three fillers-prepolymerized filler, silica } \\
\text { nanofillers }(20-50 \mathrm{~nm}) \text {, and barium glass } \\
(0.4 \mu \mathrm{m})\end{array}$ & Up to 78 wt $\%$ \\
\hline $\begin{array}{l}\text { Tetric N-Ceram } \\
\text { Bulk Fill }\end{array}$ & $\begin{array}{l}\text { IvoclarVivadent, } \\
\text { Schaan, } \\
\text { Liechtenstein }\end{array}$ & $\begin{array}{l}\text { Dimethacrylates } 21.0 \% \\
\text { (bis-GMA, bis-EMA, } \\
\text { UDMA) }\end{array}$ & $\begin{array}{l}\text { Prepolymer filler } 17.0 \% \text { (glass filler, ytterbium } \\
\text { trifluoride), Ba-Al-Si glass, mixed oxide } 61.0 \% \text {, } \\
\text { additive, initiators, stabilizers, pigments, } 1.0 \%\end{array}$ & $\begin{array}{l}\text { Up to } 79-81 \mathrm{wt} \\
\% / 60-61 \mathrm{vol} \%\end{array}$ \\
\hline $\begin{array}{l}\text { NanoCeram } \\
\text { Bright }\end{array}$ & DMP & $\begin{array}{l}\text { Organically modified } \\
\text { ceramic nanoparticles }\end{array}$ & $\begin{array}{l}\text { A special blend of micro- and nanofillers of } \\
\text { average particle size of } 20 \mathrm{~nm} \text { Glass filler size } \\
\text { (mean) } \mu \mathrm{m} 1.2-1.6\end{array}$ & $\begin{array}{l}\text { Up to } 77 \text { wt } \% / 55 \\
\text { vol } \%\end{array}$ \\
\hline $\begin{array}{l}\text { Materials' } \\
\text { description }\end{array}$ & Brand names & Composition & & Manufacturer \\
\hline $\begin{array}{l}\text { One-component } \\
\text { primer }\end{array}$ & Monobond plus & \multicolumn{2}{|c|}{$\begin{array}{l}\text { An alcohol solution of silane methacrylate, phosphoric acid, methacrylate } \\
\text { and sulfide methacrylate }\end{array}$} & $\begin{array}{l}\text { Ivoclar Vivadent, } \\
\text { USA }\end{array}$ \\
\hline
\end{tabular}


placed at an angle of $90^{\circ}$ to the surface at a working distance of $5 \mathrm{~mm}$ from the samples for 10 seconds.

Subgroup B: The composite sample surfaces were roughened with coarse grit diamond bur $140 \mu \mathrm{m}$ mean particle size (KG Sorensen SP, Brazil). The surfaces were roughened with three strokes using high-speed handpiece and water spray.

Subgroup C: The composite surfaces were etched with 10\% hydrofluoric acid (Angelus porcelain etch gel) for 30 seconds, rinsed with water, and dried.

Subgroup D: Control group with no surface treatment performed on the samples.

\section{Profilometric Evaluation}

Surface topography and surface roughness $(\mathrm{Ra})$ of each surface-treated samples from all the groups were evaluated using 3D optical profilometer (PGI Matrix-Taylor Holoson UK Ametek; Cipet, Chennai).A silane coupling agent (Monobond Plus) was applied for 1 minute and dried for 10 seconds with compressed air in all surfacetreated samples. An adhesive agent (Kerr Optibond) was applied using applicator tip, thinned with compressed air, and light cured for 20 seconds. Composite blocks were again placed in the split mold.

A repair mold was fabricated with a height of $5 \times 3 \mathrm{~mm}$ in diameter for preparation of repair composite blocks. Repair mold was placed on the split mold, and composite blocks were restored with the respective nanohybrid composite resins (A2 shades) in an increment of $2 \mathrm{~mm}$ thickness. A mylar strip was placed over the last increment and light cured for 20 seconds with an LED light curing unit at the light intensity of 800 to $1000 \mathrm{~mW} / \mathrm{cm}^{2}$. The samples were then stored in distilled water at $37^{\circ} \mathrm{C}$ for 1 week.

\section{Shear Bond Test}

The samples were mounted in acrylic resin. A shearing force test was performed using Hounsfield universal testing machine (Instron, USA) with a software program. A shearing blade of thickness $0.5 \mathrm{~mm}$ was placed parallel to the adhesive interface. A load was applied to the interface. The crosshead speed of the load was $0.5 \mathrm{~mm} /$ minute until fracture.

\section{Statistical Analysis}

Analyses were performed using two-way ANOVA and post hoc Tukey test. The data were analyzed descriptively to obtain the mean and standard deviations for each group.

\section{RESULTS}

The mean and standard deviation of repair bond strength of each group and subgroup were given in Table 2.
Table 2: The mean and standard deviation of repair bond strength of each group and subgroup

\begin{tabular}{|c|c|c|c|c|c|}
\hline Groups & & $n$ & Mean & $\begin{array}{l}\text { Standard } \\
\text { deviation }\end{array}$ & $p$-value \\
\hline \multicolumn{6}{|c|}{ Intergroup comparisons } \\
\hline \multirow[t]{5}{*}{ Kerr_Composite } & HFA & 5 & 157.1300 & 19.63832 & $<0.001^{*}$ \\
\hline & SB & 5 & 317.5586 & 39.94458 & \\
\hline & Bur & 5 & 185.9744 & 5.38522 & \\
\hline & Control & 5 & 125.7020 & 5.80618 & \\
\hline & Total & 20 & 196.5913 & 77.73682 & \\
\hline \multirow[t]{5}{*}{ Nano_Composite } & HFA & 5 & 136.6484 & 13.57708 & $<0.001^{*}$ \\
\hline & SB & 5 & 201.5432 & 18.99491 & \\
\hline & Bur & 5 & 187.3766 & 33.69399 & \\
\hline & Control & 5 & 116.8640 & 5.18342 & \\
\hline & Total & 20 & 160.6081 & 40.54136 & \\
\hline \multirow[t]{5}{*}{ Tetric_Composite } & HFA & 5 & 202.7290 & 27.04982 & $<0.001^{*}$ \\
\hline & SB & 5 & 222.3742 & 19.07573 & \\
\hline & Bur & 5 & 196.0174 & 24.63550 & \\
\hline & Control & 5 & 90.6400 & 19.11607 & \\
\hline & Total & 20 & 177.9402 & 56.64130 & \\
\hline
\end{tabular}

p-value based on ANOVA; ${ }^{*} p<0.05$ (statistically significant)

Highest shear bond strength was observed in nanohybrid composite surface treated with sandblasting (subgroup A) followed by composites surface treated with bur (subgroup B) and hydrofluoric acid (subgroup C). The lowest shear bond strength was observed in the control group (subgroup D).

\section{DISCUSSION}

The ultimate goal of repairing composite restoration is to achieve adequate bond strength between old and new material, to improve the adhesive resistance of repair material. In the present study, highest repair bond strength values were observed in subgroups that were surface treated. Roughening composite surface by either sandblasting, bur, or etching can increase the bond to the repaired composite. The control group without any surface treatment showed the lowest repair bond strength values. ${ }^{19}$ Adhesion between the aged and repair composite occurs by a mechanical surface treatment that produces surface roughness facilitating micromechanical interlocking to the repaired composite. Adhesion was also achieved by chemical bonding with the resin matrices and exposed filler particles.

Shear bond strength tests are the most commonly used by the researchers to evaluate the adhesion properties of the adhesive systems. The shear test is a better representation of the forces clinically experienced by a restoration. ${ }^{20}$

Aged composites have decreased unreacted $C=C$ double bonds after 24 hours, and it undergoes hydrolytic degradation of filler particles and crack formation within matrix due to water absorption. It signifies the importance 
of surface treatment for adhesion of repair composite over the aged composite.

Regarding the effect of surface treatment, the results of the current study revealed that the subgroups treated with sandblasting showed higher statistically significant shear bond strength value regardless of the material used. ${ }^{10,14}$ The reason behind was that sandblasting results in incorporation of silica particles into the resin matrix, and application of silane coupling agent results in a silanized coating on the glass filler particles, and silica nanofillers present in Kerr composite promotes chemical bonding with the resin matrix. ${ }^{11,18,19}$

Sandblasting the surface followed by silane application resulted in increased shear bond strength because Si-O group absorbs strongly to the silica particles that promote wetting and increase infiltration of resin into the roughened surface of the substrate. In the present study, extraoral sandblaster was used for testing the shear bond strength. In the clinical settings, intraoral sandblaster can be used to achieve significant bond strength.,21

Surface treatment using rotary diamond burs produce micromechanical interlocking, and it increases the surface area for bonding. Roughness pattern created by bur and sandblasting was entirely different when evaluated using optical 3D profilometer. ${ }^{3}$ Surface treatment using bur created unidirectional peak and valleys, but sandblasted surface created more 3D roughness with varying peak and valleys.

Tetric N-Ceram composite surface treated with hydrofluoric acid showed higher shear bond strength when compared with other nanohybrid composites. ${ }^{22}$ These differences can be due to differences in percentage and type of inorganic fillers used. Nanohybrid composites have submicron silica fillers and zirconia particles. ${ }^{19,21,23}$ HF3 etching promotes micromechanical interlocking and silica-containing fillers are partially exposed due to etching, and the silane agent reacts with silica particles. Thus, it facilitates better shear bond strength in nanohybrid composites. ${ }^{24}$

Nanohybrid composite resins have nano-sized filler particles and higher filler content that provides better esthetic properties, high polishability and low polymerization shrinkage. Three different nanohybrid composites were chosen in the present study. The reason behind this was that the ${ }^{14}$ composition of the organic matrix and inorganic fillers of different composite resins plays a role in chemical bonding to the repair composites during relayering. Composite to composite adhesion of varying nanohybrid has not been commonly investigated. ${ }^{25}$ Surface treatment, such as mechanical roughening and silane treatment followed by adhesive resin placement was found to be quite efficient in the repair of microhybrid resins; however, similar improvements could not be achieved in the repair of nanohybrid composites. This has been explained with the high conversion degree of the polymerized resin, limiting the number of available unreacted $\mathrm{C}=\mathrm{C}$ bonds. ${ }^{26}$ The repair bond strength of nanohybrid composites may mainly depend on the micromechanical retention between old and new composite layers.

Moreover, particle sizes of different composites may influence bond strength. Even though studies are available to evaluate the mechanical properties, flexural strength, and color stability, not much of literature is available to assess the adhesive resistance after repair. ${ }^{27}$ Rodrigues et $\mathrm{al}^{27}$ observed that the differences in the microstructure of resin composite influence average bond strength values and a nanoparticle composite resin displays an inferior bond strength compared with microhybrid composite resin. ${ }^{28}$ Spyrou et al ${ }^{28}$ observed differences in repair strength of composites based on different resin compositions.

All surface treatments produced improved shear bond strength to the repaired composite when compared with the control group and considered to be appropriate.

A shortcoming of this study was that ${ }^{29}$ microshear bond strength test almost wholly substituted the shear bond test, the main characteristic of which is the reduced specimen size, and the specimens might be readily prepared. It is also verified that different values are achieved for different bonding areas: the smaller the area, the higher the bond strength.

Due to high shrinkage, composite repairs may start to crack after relatively short time in service. There are no long-term studies available to validate this shortcoming. It is appropriate that clinical investigations take place to assess the longevity of repaired restorations. There is a need for methodologically sound randomized long-term clinical trials to be able to give an evidence-based recommendation.

\section{CONCLUSION}

Within the limitations of this study, the following conclusions could be drawn for the tested materials: Composite surfaces treated with sandblasting, bur, and hydrofluoric acid increase the bond strength when compared with the nonsurface-treated groups in the composite to repair composite interface.

Sandblasting surface treatment of Kerr composite manifested the highest bond strength, followed by Tetric $\mathrm{N}-\mathrm{Ceram}$ and NanoCeram groups. Bur surface treatment of Tetric N-Ceram composite showed the higher bond strength values compared with the other groups. Hydrofluoric acid surface treatment of NanoCeram composite presented inferior bond strength values, and Tetric $\mathrm{N}$-Ceram composites showed the higher values. 
Repair bond strength of aged nanohybrid resins could be improved with sandblasting, silane, and adhesive resin application compared with other surface treatments.

\section{REFERENCES}

1. Akova T, Ozkomur A, Uysal H. Effect of food-simulating liquids on the mechanical properties of provisional restorative materials. Dent Mater 2006 Dec;22(12):1130-1134.

2. Cho SD, Rajitrangson P, Matis BA, Platt JA. Effect of Er,Cr:YSGG laser, air abrasion, and silane application on the repaired shear bond strength of composites. Oper Dent 2013 May-Jun;38(3):E1-E9.

3. da Costa TR, Serrano AM, Atman AP, Loguercio AD, Reis A. Durability of composite repair using different surface treatments. J Dent 2012 Jun;40(6):513-521.

4. Moncada G, Fernandez E, Martín J, Arancibia C, Mjör IA, Gordan VV. Increasing the longevity of restorations by minimal intervention: a two-year clinical trial. Oper Dent 2008 May-Jun;33(3):258-264.

5. Dall'Oca S, Pappacchini F, Goracci C, Cury AH, Suh BI, Tay FR, Polimeni A, Ferrari M. Effect of oxygen inhibition on composite repair strength over time. J Biomed Mater Res B Appl Biomater 2007 May;81(2):493-498.

6. Li J. Effects of surface properties on the bond strength between layers of newly cured dental composites. J Oral Rehabil 1997 May;24(5):358-360.

7. Özcan M, Pekkan G. Effect of different adhesion strategies on bond strength of resin composite to composite-dentin complex. Oper Dent 2013 Jan-Feb;38(1):63-72.

8. Rossato DM, Bandaca MC, Saada EG, Lizarelli RFZ, Bagnato VS, Saad JR. Influence of Er: YAG laser on surface treatment of aged composite resin to repair restoration. Laser Physics 2009 Nov;19:2144-2149.

9. Bacchi A, Consani RL, Sinhoreti MA, Feitosa VP, Cavalcante LM, Pfeifer CS, Schneider LF. Repair bond strength in aged methacrylate and silorane- based composites. J Adhes Dent 2013 Oct;15(5):447-452.

10. Özcan M, Corazza PH, Marocho SM, Barbosa SH, Bottino MA. Repair bond strength of microhybrid, nanohybrid and nanofilled resin composite: effect of substrate resin type, surface conditioning and aging. Clin Oral Invest 2013 Sep;17(7): 1751-1758.

11. Ozcan M, Barbosa SH, Melo RM, Galhano GA, Bottino MA. Effect of surface conditioning methods on the micro-tensile bond strength of resin composite to composite after aging conditions. Dent Mater 2007 Oct;23(10):1276-1282.

12. Bonstein T, Garlapo D, Donarummo J Jr, Bush PJ. Evaluation of varied repair protocols applied to aged composite resin. J Adhes Dent 2005 Spring;7(1):41-49.

13. Costa TR, Ferreira SQ, Klein-Junior CA, Loguercio AD, Reis A. Durability of surface treatments and intermediate agents used for repair of a polished composite. Oper Dent 2010 Mar-Apr; 35(2):231-237.

14. Rinastiti M, Özcan M, Siswomihardjo W, Busscher HJ. Effects of surface conditioning on repair bond strengths of non-aged and aged micro hybrid, nanohybrid, and nanofill composite resins. Clin Oral Invest 2011 Oct;15(5):625-633.

15. Alizadeh Oskoee P, Mohammadi N, Ebrahimi chaharom ME, Kimyai S, Pournaghi Azar F, Rikhtegaran S, Shojaeei M. Effect of surface treatment with Er;Cr:YSSG, Nd:YAG, and $\mathrm{CO}_{2}$ lasers on the repair shear bond strength of a silorane-based composite resin. J Dent Res Dent Clin Dent Prospects 2013 Spring;7:61-66.

16. Rathke A, Tymina Y, Haller B. Effect of different surface treatments on the composite-composite repair bond strength. Clin Oral Investig 2009 Sep;13(3):317-323.

17. Lung CY, Matinlinna JP. Aspects of silane coupling agents and surface conditioning in dentistry: an overview. Dent Mater 2012 May;28(5):467-477.

18. Rinastiti M, Ozcan M, Siswomihardjo W, Busscher HJ. Immediate repair bond strengths of micro hybrid, nanohybrid and nanofilled composites after different surface treatments. J Dent 2010 Jan;38(1):29-38.

19. Loomans BA, Cardoso MV, Roeters FJ, Opdam NJ, De Munck J, Huysmans MC, Van Meerbeek B. Is there one optimal repair technique for all composites? Dent Mater 2011 Jul;27:701-709.

20. Brendeke J, Ozcan M. Effect of physicochemical aging conditions on the composite-composite repair bond strength. J Adhes Dent 2007 Aug;9(4):399-406.

21. Hemadri M, Saritha G, Rajasekhar V, Pachlag KA, Purushotham R, Reddy VK. Shear bond strength of repaired composites using surface treatments and repair materials: an in vitro study. J Int Oral Health 2014 Nov-Dec;6(6):22-25.

22. Brosh T, Pilo R, Bichacho N, Blutstein R. Effects of combinations of surface treatments and bonding agents on the bond strength of repaired composites. J Prosthet Dent 1997 Feb;77(2): 122-126.

23. Yesilyurt C, Kusgoz A, Bayram M, Ulker M. Initial repair bond strength of a nano-filled hybrid resin: effect of surface treatments and bonding agents. J Esthet Restor Dent 2009 Aug;21(4):251-260.

24. Jung M, Sehr K, Klimek J. Surface texture of four nanofilled and one hybrid composite after finishing. Oper Dent 2007 Jan-Feb;32(1):45-52.

25. Jafarzadeh Kashi TS, Erfan M, Rakhshan V, Aghabaigi N, Tabatabaei FS. An in vitro assessment of the effects of three surface treatments on repair bond strength of aged composites. Oper Dent 2011 Nov-Dec;36(6):608-617.

26. Staxrud F, Dahl JE. Role of bonding agents in the repair of composite resin restorations. Eur J Oral Sci 2011 Aug;119(4): 316-322.

27. Rodrigues SA Jr, Ferracane JL, Della Bona A. Influence of surface treatments on the bond strength of repaired resin composite restorative materials. Dent Mater 2009 Apr;25(4): 442-451.

28. Spyrou M, Koliniotou-Koumpia E, Kouros P, Koulaouzidou E, Dionysopoulos P. The reparability of contemporary composite resins. Eur J Dent 2014 Jul-Sep;8(3):353-359.

29. Hiraishi N, Kitasako Y, Nikaido T, Nomura S, Burrow MF, Tagami J. Effect of artificial saliva contamination on $\mathrm{pH}$ value change and dentin bond strength. Dent Mater 2003 Jul;19(5):429-434. 